\title{
Carbon dioxide inhalation as a human experimental model of panic: The relationship between emotions and cardiovascular physiology
}

Citation for published version (APA):

Leibold, N. K., Viechtbauer, W., Goossens, L., De Cort, K., Griez, E. J., Myin-Germeys, I., Steinbusch, H. W. M., van den Hove, D. L. A., \& Schruers, K. R. J. (2013). Carbon dioxide inhalation as a human experimental model of panic: The relationship between emotions and cardiovascular physiology. Biological Psychology, 94(2), 331-340. https://doi.org/10.1016/j.biopsycho.2013.06.004

Document status and date:

Published: 01/10/2013

DOI:

10.1016/j.biopsycho.2013.06.004

Document Version:

Publisher's PDF, also known as Version of record

\section{Document license:}

Taverne

Please check the document version of this publication:

- A submitted manuscript is the version of the article upon submission and before peer-review. There can be important differences between the submitted version and the official published version of record.

People interested in the research are advised to contact the author for the final version of the publication, or visit the DOI to the publisher's website.

- The final author version and the galley proof are versions of the publication after peer review.

- The final published version features the final layout of the paper including the volume, issue and page numbers.

Link to publication

\footnotetext{
General rights rights.

- You may freely distribute the URL identifying the publication in the public portal. please follow below link for the End User Agreement:

www.umlib.nl/taverne-license

Take down policy

If you believe that this document breaches copyright please contact us at:

repository@maastrichtuniversity.nl

providing details and we will investigate your claim.
}

Copyright and moral rights for the publications made accessible in the public portal are retained by the authors and/or other copyright owners and it is a condition of accessing publications that users recognise and abide by the legal requirements associated with these

- Users may download and print one copy of any publication from the public portal for the purpose of private study or research.

- You may not further distribute the material or use it for any profit-making activity or commercial gain

If the publication is distributed under the terms of Article 25fa of the Dutch Copyright Act, indicated by the "Taverne" license above, 


\title{
Carbon dioxide inhalation as a human experimental model of panic: The relationship between emotions and cardiovascular physiology
}

\author{
Nicole K. Leibold ${ }^{\mathrm{a}, \mathrm{b}, *}$, Wolfgang Viechtbauer ${ }^{\mathrm{a}, \mathrm{b}}$, Liesbet Goossens ${ }^{\mathrm{a}, \mathrm{b}}$, Klara De Cort ${ }^{\mathrm{a}, \mathrm{b}}$, \\ Eric J. Griez ${ }^{\mathrm{a}, \mathrm{b}}$, Inez Myin-Germeys ${ }^{\mathrm{a}, \mathrm{b}}$, Harry W.M. Steinbusch ${ }^{\mathrm{b}, \mathrm{c}}$, \\ Daniël L.A. van den Hove ${ }^{b, c, d}$, Koen R.J. Schruers ${ }^{a, b, e}$ \\ ${ }^{a}$ Department of Psychiatry and Psychology, Maastricht University, P.O. Box 616, 6200 MD Maastricht, The Netherlands \\ b School for Mental Health and Neuroscience, Maastricht University, European Graduate School of Neuroscience (EURON), P.O. Box 616, 6200 MD \\ Maastricht, The Netherlands \\ ${ }^{\mathrm{c}}$ Department of Neuroscience, Maastricht University, P.O. Box 616, 6200 MD Maastricht, The Netherlands \\ ${ }^{\mathrm{d}}$ Department of Psychiatry and Psychotherapy, Laboratory of Translational Neuroscience, University of Würzburg, Fuechsleinstrasse 15, 97080 Würzburg, \\ Germany \\ e Department of Healthy Psychology, University of Leuven, Tiensestraat 102, P.O. Box 3726, 3000 Leuven, Belgium
}

\section{A R T I C L E I N F O}

\section{Article history:}

Received 23 August 2012

Accepted 19 June 2013

Available online 28 June 2013

\section{Keywords:}

Fear

Anxiety

$\mathrm{CO}_{2}$

Blood pressure

Heart rate

\begin{abstract}
A B S T R A C T
Inhaling carbon dioxide $\left(\mathrm{CO}_{2}\right)$-enriched air induces fear and panic symptoms resembling real-life panic attacks, the hallmark of panic disorder. The present study aimed to describe the emotional and cardiovascular effects evoked by inhaling $\mathrm{CO}_{2}$, taking shortcomings of previous studies into account. Healthy volunteers underwent a double inhalation of $0,9,17.5$, and $35 \% \mathrm{CO}_{2}$, according to a randomized, crossover design. In addition to fear, discomfort, and panic symptom ratings, blood pressure and heart rate were continuously monitored. Results showed a dose-dependent increase in all self-reports. Systolic and diastolic blood pressure rose with increasing $\mathrm{CO}_{2}$ concentration, whereas heart rate results were less consistent. Diastolic blood pressure and heart rate variation correlated with fear and discomfort. Based on this relationship and the observation that the diastolic blood pressure most accurately mimicked the degree of self-reported emotions, it might serve as a putative biomarker to assess the $\mathrm{CO}_{2}$-reactivity in the future.
\end{abstract}

(c) 2013 Elsevier B.V. All rights reserved.

\section{Introduction}

About $23 \%$ of the general population experiences a panic attack (PA) at least once in their lives (Kessler et al., 2006). PAs are spontaneous periods of irrational intense fear and/or discomfort accompanied by respiratory, neurovegetative and cognitive symptoms such as shortness of breath, choking, dizziness, palpitations, chest pain, paresthesias, fear of losing control, and derealization.

\footnotetext{
* Corresponding author at: Department of Psychiatry and Psychology, Maastricht University, P.O. Box 616 (Vijv), 6200 MD Maastricht, The Netherlands. Tel.: +31043 3883511; fax: +310433884122.

E-mail addresses: nicole.leibold@maastrichtuniversity.nl (N.K. Leibold), wolfgang.viechtbauer@maastrichtuniversity.nl (W. Viechtbauer), lies.goossens@maastrichtuniversity.nl (L. Goossens), klaradecort@skynet.be (K. De Cort), eric.griez@maastrichtuniversity.nl (E.J. Griez), i.germeys@maastrichtuniversity.nl (I. Myin-Germeys), h.steinbusch@maastrichtuniversity.nl (H.W.M. Steinbusch), d.vandenhove@maastrichtuniversity.nl (D.L.A. van den Hove), koen.schruers@maastrichtuniversity.nl (K.R.J. Schruers).
}

The symptomatic peak is reached within 10 min after onset of the attack.

Recurrent PAs form the core of panic disorder (PD). In addition to PAs, PD is characterized by concerns about future attacks or concomitant consequences, often accompanied by behavioral changes (American Psychiatric Association, 2000). PD has a prevalence of about $4 \%$ in the general population (Weissman et al., 1997) and is accompanied by a considerable decrease in quality of life and high health care costs (Andlin-Sobocki \& Wittchen, 2005; Olesen, Gustavsson, Svensson, Wittchen, \& Jonsson, 2012). In spite of a large amount of research into the underlying mechanisms of panic, there is still no scientific consensus on its pathogenesis.

From a biological point of view, converging evidence points towards a role of chemosensitivity in the pathophysiology of PAs. An early theory was postulated by Klein (1993; Preter \& Klein, 2008), stating that every individual is equipped with a phylogenetically evolved suffocation alarm system that is sensitive to metabolic threats from bodily origin (e.g., $\mathrm{CO}_{2}$ levels and $\mathrm{CO}_{2}-$ induced changes in $\mathrm{pH}$ ). When activated, the individual is alerted of imminent asphyxia, leading to an emotional and behavioral response such as acute panic. An erroneous triggering of the alarm 
system, however, signals a vital threat without the presence of a real danger. In other words, according to Klein's theory, PAs are false alarms due to a dysfunctional suffocation detection. However, a neural substrate for that suffocation detector system remains to be elucidated.

On a molecular level, it has been shown that brainstem serotonergic cells act as chemosensors that detect a decrease in $\mathrm{pH}$ due to an increased concentration of $\mathrm{CO}_{2}$ (Corcoran et al., 2009; Richerson, 2004; Severson, Wang, Pieribone, Dohle, \& Richerson, 2003). These serotonergic cells are closely associated with large arteries, thereby being ideally situated to sense arterial blood $\mathrm{CO}_{2}$ levels and to initiate behavioral and autonomic responses aimed at maintaining $\mathrm{pH}$ homeostasis (Bradley et al., 2002). As projection areas of these cells include the limbic system, it has been suggested that these serotonergic cells are involved in the affective response to $\mathrm{CO}_{2}$. In this respect, these cells may mediate arousal and feelings of anxiety and suffocation to $\mathrm{CO}_{2}$ (Richerson, 2004).

A recent study further increased the insights into the mechanisms underlying the effects of $\mathrm{CO}_{2}$. In this rodent study, it was demonstrated that the acid-sensing ion channel 1a (ASIC1a) also detects changes in $\mathrm{pH}$. Exposure to $\mathrm{CO}_{2}$ was shown to reduce the $\mathrm{pH}$ within the amygdala, which activates amygdalar ASIC1a that, in turn, is strongly involved in triggering fear behavior (Ziemann et al., 2009). These data are in accordance with a previous hypothesis that PAs might involve an acute disturbance in the acid-base balance in certain brain areas (Esquivel, Schruers, Maddock, Colasanti, \& Griez, 2010).

We have previously proposed (in line with Denton, 2006; Denton, McKinley, Farrell, \& Egan, 2009) that PAs can be considered as the expression of an emotion aimed at maintaining the individual's homeostasis. In this view, emotions consist of two components, namely sensation and intention. Sensation is the conscious perception of disturbed bodily functions, stimulating an adaptive response (intention). When the sensation is evoked by internal body states (i.e., interoceptor driven) and is linked to survival, thus signaling that the organism's existence is instantly threatened, the emotion may pervade the conscious awareness as primal emotion (Colasanti, Esquivel, Schruers, \& Griez, 2012; Denton, 2006; Denton et al., 2009). In this respect, we believe that PAs are rooted in instinctual behavior and are an instance of primal emotion to protect the individual against a vital threat. Therefore, it would be meaningless to assess PAs using exclusively biological or psychological measures.

PAs can be reliably provoked in the laboratory. Numerous pharmacological substances and other techniques have been used (for review see Esquivel, Schruers, \& Griez, 2008), of which some influence the acid-base homeostasis: voluntary hyperventilation, lactate infusions, and carbon dioxide $\left(\mathrm{CO}_{2}\right)$ inhalations.

When comparing the different methods, it is apparent that $\mathrm{CO}_{2}$ inhalation has a number of advantages, which made it an often applied and well-established experimental model for human panic during the last few decades. $\mathrm{CO}_{2}$ inhalation is a relatively easy, non-invasive, safe, and reliable technique to trigger intense, but short-lasting, fear and panic symptoms in PD patients (e.g., Nardi et al., 2006; Perna, di Bella, et al., 2004; Verburg, Griez, Meijer, \& Pols, 1995; Verburg, Pols, de Leeuw, \& Griez, 1998). These sensations closely resemble the symptomatology of naturally occurring PAs (Nardi et al., 2006; Schruers, van de Mortel, Overbeek, \& Griez, 2004). Over the last few years, it has been shown that panic can also be induced in healthy subjects by inhaling $\mathrm{CO}_{2}$. More specifically, $\mathrm{CO}_{2}$ dose-dependently elicits negative affect, provoking the emotional and physical sensations of a PA in accordance with the formal DSM-IV criteria, particularly when using a double vital capacity breath of $35 \% \mathrm{CO}_{2}$ (Colasanti et al., 2008; Griez, Colasanti, van Diest, Salamon, \& Schruers, 2007; Schruers et al., 2011). These studies demonstrate that panic symptoms can, to a differing extent, be triggered in most individuals, depending on the concentration of $\mathrm{CO}_{2}$ used. This implies the existence of a $\mathrm{CO}_{2}$-reactivity continuum and that the response to $\mathrm{CO}_{2}$ is based on a common mechanism. Therefore, studying healthy volunteers can provide important insights into the fundamental mechanisms underlying $\mathrm{CO}_{2}$-reactivity. Additional reasons to investigate the basic mechanisms of panic in healthy volunteers are the high comorbidity with other psychiatric disorders and the frequent use of medication by PD patients, both of which may mask the effects of interest.

The response to $\mathrm{CO}_{2}$ is commonly measured using self-reports on the presence and intensity of fear and panic symptoms. PAs are accompanied by profound physiological symptoms that are also classically assessed by self-reports. A primal emotion consists of the conscious perception of disturbed bodily function as well as an adaptive homeostatic response. The former can be reported by the individual, whereas the latter is not completely covered by self-reports. Therefore, focusing on the classical self-reports seems too narrow to examine a PA in all its aspects. Incorporating physiological measures may be an important approach to assess the homeostatic response and to complement selfratings, thereby refining the assessment and diagnosis of PAs. In recent years, various (psycho)physiological parameters have been increasingly included (e.g., Bailey, Argyropoulos, Kendrick, \& Nutt, 2005; Blechert, Wilhelm, Meuret, Wilhelm, \& Roth, 2010, 2013; Bystritsky, Craske, Maidenberg, Vapnik, \& Shapiro, 2000; Gorman et al., 2001; Papadopoulos, Rich, Nutt, \& Bailey, 2010; Pappens, De Peuter, Vansteenwegen, Van den Bergh, \& Van Diest, 2012; Poma et al., 2005).

When focusing on the cardiovascular system, blood pressure and heart rate are the parameters of interest. More than two decades ago, some attempts were already made to include those measurements to assess the cardiovascular response to a $\mathrm{CO}_{2}$ inhalation. For instance, in PD patients and controls, Gorman et al. (1990) did not find any significant alteration in blood pressure after inhaling 35\% $\mathrm{CO}_{2}$. Similarly, Bystritsky and Shapiro (1992) did not observe any blood pressure response in healthy subjects, when inhaling a low dosage of $5.5 \% \mathrm{CO}_{2}$. However, small sample sizes and analyzing means over prolonged periods of time (Gorman et al., 1990) limit the generalizability of these results. Using larger samples, other research groups did report $\mathrm{CO}_{2}$-induced increases in blood pressure (Martinez et al., 1998) and heart rate (Martinez et al., 1998; Poonai et al., 2000). Using more advanced beat-to-beat monitoring revealed that $35 \% \mathrm{CO}_{2}$ elicited a relative rise in systolic blood pressure, whereas heart rate was not affected, when comparing the change between $10 \mathrm{~s}$ before to $10 \mathrm{~s}$ after the $\mathrm{CO}_{2}$ inhalation. Analyzing the first post-inhalation minute showed a relative $\mathrm{CO}_{2}$-induced rise of the systolic blood pressure, concomitant with an overall decrease of heart rate, possibly compensatory to the elevated blood pressure (Argyropoulos et al., 2002). A correlation analysis on these data yielded no significant relationship between cardiovascular parameters and self-reported fear (Bailey, Argyropoulos, Lightman, \& Nutt, 2003). Further, in other studies, an increase in systolic (Bailey et al., 2005; Kaye et al., 2004; Wetherell et al., 2006), but not diastolic (Bailey et al., 2005; Kaye et al., 2004), blood pressure was reported after inhaling $\mathrm{CO}_{2}$-enriched air. Assessing heart rate yielded inconsistent results in these studies, with reports on a positive (Bailey et al., 2005) and negative (Kaye et al., 2004; Wetherell et al., 2006) effect of a $\mathrm{CO}_{2}$ inhalation. In contrast, more recent studies observed an increase in heart rate (Nillni, Berenz, Rohan, \& Zvolensky, 2012; Papadopoulos et al., 2010; Richey, Schmidt, Hofmann, \& Timpano, 2010), but diverge regarding the effects of $\mathrm{CO}_{2}$ on blood pressure. Papadopoulos et al. (2010) did not find any effect caused by inhaling 7.5\% $\mathrm{CO}_{2}$, whereas Richey et al. (2010) reported an increase in systolic as well as diastolic blood pressure after taking a single breath of $35 \% \mathrm{CO}_{2}$. 
Taken together, the results of studies assessing the cardiovascular physiology in response to a $\mathrm{CO}_{2}$ inhalation are fairly inconsistent, which may be explained by several identifiable variations and shortcomings in terms of methodology, technical equipment, and performed analyses. For instance, an insufficient number of measurements over time accompanied by analyzing overall means or means over several seconds (e.g., Gorman et al., 1990) masks time courses and brief fluctuations, which are of importance to gain more insight into a short-lived phenomenon such as panic. Similarly to early studies, more recent studies employing beat-to-beat measurements frequently used small sample sizes and/or focused on a single concentration of $\mathrm{CO}_{2}$ (e.g., Argyropoulos et al., 2002; Bailey et al., 2003, 2005; Papadopoulos et al., 2010). In addition to methodological issues, confounders may also contribute to varying results. For instance, it has been reported that the $\mathrm{CO}_{2}$-reactivity decreases with age (Griez et al., 2007), indicating the importance of a large sample size and/or restriction of the sample's age range. Other possible confounders include, for instance, smoking (Abrams et al., 2008; Knuts et al., 2010), caffeine intake (Nardi et al., 2007; Vilarim, Rocha Araujo, \& Nardi, 2011), alcohol use (Cosci, De Gooyer, Schruers, Faravelli, \& Griez, 2005; Kushner et al., 1996), and physical exercise (Esquivel et al., 2012; Smits, Meuret, Zvolensky, Rosenfield, \& Seidel, 2009).

The objective of the present study was to describe the emotional and cardiovascular response to $\mathrm{CO}_{2}$ to assess the psychobiological phenomenon PA in all its aspects, taking the abovementioned identifiable shortcomings of previous studies into account, and thereby refining the assessment of PAs. Accordingly, to investigate the response to $\mathrm{CO}_{2}$ in more detail, we challenged 120 healthy volunteers with four different $\mathrm{CO}_{2}$ concentrations that have been proven to evoke a dose-dependent increase in negative affect. In addition to the commonly used self-reports, we used a computerized system that allowed continuous and accurate monitoring of the physiological parameters blood pressure and heart rate throughout the entire procedure. Of note, both parameters were previously validated in a pilot study. We hypothesized that the cardiovascular measures would mimic the degree of self-reported fear, discomfort, and panic symptoms.

\section{Materials and methods}

\subsection{Subjects}

One hundred and twenty healthy volunteers participated in this study (35 males, 85 females, mean age 24.01 years, $S D=7.24$ ). Subjects were recruited via advertisements at Maastricht University, the Netherlands, to ensure a homogenous sample in terms of age (Griez et al., 2007). All potential subjects were screened by an experienced psychiatrist or psychologist using a routine medical examination and the Mini International Neuropsychiatric Interview (M.I.N.I., Sheehan et al., 1998). Inclusion criteria were age between 18 and 65 years, and a good past and present physical as well as mental condition. Exclusion criteria were current or past pulmonary or cardiovascular disease, current hypertension (systolic $>170 \mathrm{mmHg}$, diastolic $>100 \mathrm{mmHg}$ ), cerebral aneurysm, pregnancy, epilepsy, excessive smoking (>15 cigarettes/day), use of adrenergic receptor blockers or psychotropic medication, and having a first-degree relative suffering from PD. Subjects were instructed to refrain from coffee on the test days. Each subject gave written informed consent according to the principles of the Declaration of Helsinki. A financial compensation was paid for participation. The study was approved by the Medical Ethics Committee of Maastricht University and the Maastricht University Hospital.

\subsection{Procedure}

The study was performed as previously described (Griez et al., 2007; Schruers et al., 2011; Verburg, Perna, \& Griez, 2001) and extended by physiological measurements (see Section 2.4). Using a randomized, cross-over design, subjects underwent a standardized double inhalation of four $\mathrm{CO}_{2}$ concentrations: $0 \%$ (room air), $9 \%, 17.5 \%$ and $35 \% \mathrm{CO}_{2}$. Each mixture also contained $20 \% \mathrm{O}_{2}$ and $80 \%, 71 \%, 62.5 \%$, or $55 \% \mathrm{~N}_{2}$, respectively. Subjects were seated in a comfortable armchair during the entire procedure. A soft plastic nasal-oral mask, connected to a capnograph (medair, Delsbo, Sweden) and a computer, was fixed to the subjects' head. First, the vital capacity of a double breath was measured using a flowmeter. Subjects were instructed to exhale to the maximum, to inhale as much as possible, to exhale and inhale to the maximum again, and to hold their breath for $4 \mathrm{~s}$ (to increase alveolar gas exchange). Subsequently, the $\mathrm{CO}_{2}$ inhalation took place. Subjects were told that the following breath of the $\mathrm{CO}_{2}$ mixture may cause effects, ranging from some vague sensations up to fear, depending on the $\mathrm{CO}_{2}$ concentration and the individual susceptibility. However, all sensations would be short-lived. The words 'panic attack' were not mentioned to avoid cognitive bias due to expectation. The inhalation procedure was identical to the one previously used for assessing the double breath vital capacity, including the use of the same flowmeter to motivate the subjects to inhale at least $80 \%$ of the measured vital capacity. Inhalations took place on four separate days, each day at the same time for each subject, to avoid effects of fluctuations in circadian rhythms.

\subsection{Self-report measures}

Self-reports were assessed in accordance with the DSM-IV criteria, which define a PA as 'a discrete period of intense fear or discomfort', accompanied by at least 4 out of 13 defined symptoms that develop abruptly and reach a peak within 10 min after onset (American Psychiatric Association, 2000). In line with this definition, subjects were asked to evaluate their subjective feeling of fear and discomfort by means of a Visual Analogue Scale (VAS-Fear and VAS-Discomfort, respectively). The scale consists of a horizontal line of $100 \mathrm{~mm}$ length and ranges from 0 (not at all) to 100 (the worst imaginable). Panic symptoms were evaluated using the Panic Symptom List (PSL)-IV, which lists the 13 symptoms characterizing a PA according to the DSMIV criteria such as palpitations, shortness of breath, feeling of chocking, dizziness, and fear of losing control or of dying. The list ranges from 0 (absent) to 4 (very intense).

Self-reports were obtained immediately before (how the subjects felt at that particular moment) and immediately after the $\mathrm{CO}_{2}$ inhalation (how the subjects felt at the worst moment of the inhalation) (Schruers et al., 2011). An increase of at least 25 in the fear or discomfort rating in combination with an increase of at least four points in the panic symptom rating was defined as occurrence of a PA (Esquivel et al. 2012).

\subsection{Cardiovascular measures}

Blood pressure and heart rate were continuously measured throughout the entire procedure (baseline, $\mathrm{CO}_{2}$ inhalation, recovery) using a computerized system (Carbon Dioxide Tolerance Tester, CTT, Maastricht Instruments B.V., Maastricht, The Netherlands). A finger cuff was attached to the mid-phalanx of the third finger of the non-dominant hand and was connected to a cardiovascular monitor (Nexfin, bmeye $\mathrm{BV}$, Amsterdam, The Netherlands) and a computer equipped with the software $\mathrm{CO}_{2}$ Challenge (IDEEQ, Maastricht Instruments B.V., Maastricht, The Netherlands). All measurements were calibrated and subsequently recorded using a sampling rate of $2 \mathrm{~Hz}$. To minimize movements, the hand rested on the arm of the chair.

The parameters of interest were chosen based on a previous pilot study (unpublished data), in which we assessed blood pressure, heart rate, various respiratory parameters, skin conductance, and pupil diameter in response to inhaling $35 \% \mathrm{CO}_{2}$. Blood pressure and heart rate appeared to be the most sensitive outcome parameters (in addition to respiration rate and end-tidal $\mathrm{CO}_{2}$, which were also measured but will be discussed in a separate paper) and were incorporated in a customized computerized system prior to this study.

\subsection{Statistical analysis}

Due to technical failure in the physiological monitoring in at least one of the four $\mathrm{CO}_{2}$ concentrations, 16 subjects were excluded. The final sample for all analyses with regard to physiology consisted, therefore, of 104 subjects ( 30 males, mean age 24.57 years, $S D=7.21 ; 74$ females mean age 23.20 years, $S D=6.01$ ). Changes (pre-score subtracted from post-score) in fear, discomfort, and panic symptoms across the four $\mathrm{CO}_{2}$ concentration levels were examined by means of multilevel models (with the four responses nested within subjects) with an unstructured variance-covariance matrix to account for the fact that the same subjects were tested under all four conditions. A significant overall test suggesting differences between at least two of the four $\mathrm{CO}_{2}$ concentration levels was followed up by tests of all pairwise differences using Holm's method to control the familywise error rate (Holm, 1979).

Physiological measures were analyzed in terms of systolic and diastolic blood pressure and heart rate. To reduce the amount of data, we first used locally weighted polynomial regression (Cleveland \& Devlin, 1988) for the data of each subject in order to avoid strong effects of outliers. Based on the smoothed data, we then calculated the area under the curve (AUC), peak, and range (peak minus minimum) within the first $60 \mathrm{~s}$ after inhaling the second breath of $\mathrm{CO}_{2}$ (see Supplementary Fig. 1 for an illustration of the outcomes). In addition, the amount of fluctuations around the smoothed data (standard deviation, SD) was calculated. To avoid confusion with the term "heart rate variability", which is usually assessed by means of spectrum or spectral analysis, fluctuations are denoted as "variation". These derived outcomes were then again analyzed with multilevel models as described previously. A log transformation was applied to the outcome variation to obtain residual distributions closer to normality. 

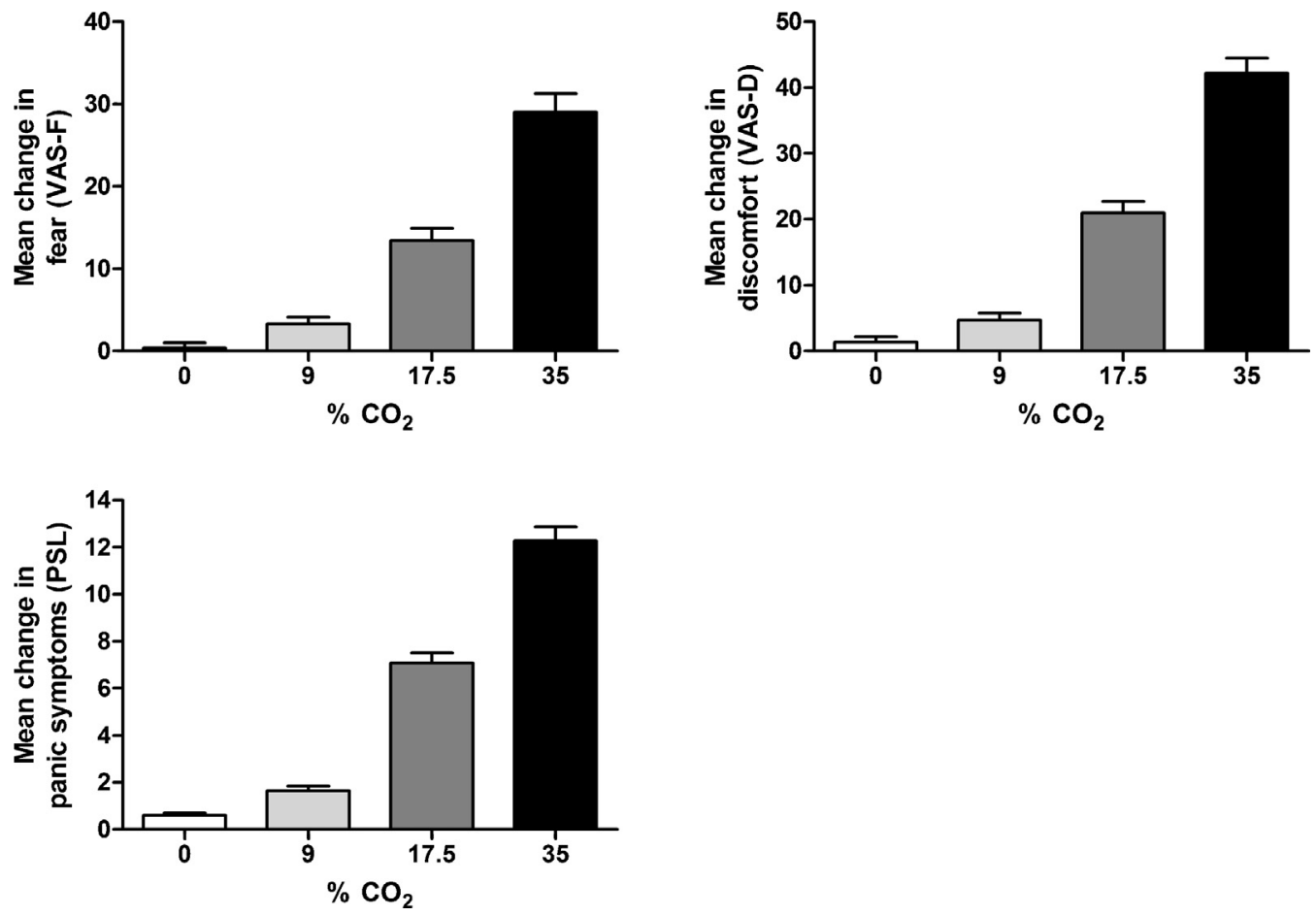

Fig. 1. Effects of increasing $\mathrm{CO}_{2}$ concentrations on the change in fear (VAS-F, top left), discomfort (VAS-D, top right) and panic symptoms (PSL, bottom). A main effect of CO 2 concentration on fear, discomfort and panic symptoms was observed ( $p<0.001$, multilevel models). $\mathrm{CO}_{2}$ increased both emotions and panic symptoms dose-dependently ( $p<0.001$, except for fear and discomfort when comparing $9 \%$ to $0 \%, p=0.006$ and $p=0.015$, respectively; pairwise comparisons using Holm's method, corrected for multiple testing). Bars represent mean change + standard error of the mean.

Effect sizes (Cohen's $d$ ) were calculated using standardized mean gains, indicating the change in the mean standardized by the standard deviation of the scores for the lower $\mathrm{CO}_{2}$ concentration (Becker, 1988).

To assess the proportion of subjects who did not recover, that is, who did not return to a stable blood pressure or heart rate within $60 \mathrm{~s}$ after inhaling $\mathrm{CO}_{2}$, we fitted rolling regression models to the data with a $20 \mathrm{~s}$ window. Within each time window, the slope of the regression line and the residual standard deviation were obtained. Stability was defined as the first 20 s window, in which the slope was below 0.10 in absolute value and the residual SD below 5.0 (see Supplementary Fig. 1). Then, Cox proportional hazard models were applied, in which robust estimators of the standard errors were used to account for the fact that subjects were measured in all four $\mathrm{CO}_{2}$ concentrations. When significant, main effects were further analyzed by means of pairwise comparisons using Holm's method.

Correlation analyses between the change in self-reports and the derived cardiovascular outcome measures were performed using a permutation test, which accounts for the fact that each subject took part in all four $\mathrm{CO}_{2}$ inhalations, thereby leading to dependent values. First, the blocks of four values belonging to the same subjects were permutated. Subsequently, the four values were permutated within each block for each subject. This process was repeated 100,000 times, after which the proportion of correlations that were more extreme than the observed correlation was calculated.

To examine whether the presence of any carry-over effects may have influenced the conclusions of the previous analyses, a four-level factor was coded that indicated the sequence of treatments given (Senn, 2002). This factor was included in the model together with its interaction with the factor of the actual $\mathrm{CO}_{2}$ concentration.

All presented $p$-values are already adjusted for multiple testing. For all analyses, significance was set at $p<0.05$. Statistical analyses were performed using the software R (version 2.14.0, 2011, R Development Core Team, Vienna/Austria). For the multilevel models, the nlme package was used (version 3.1-102).

\section{Results}

\subsection{Effects of $\mathrm{CO}_{2}$ on self-report measures}

A significant main effect of $\mathrm{CO}_{2}$ concentration on subjective fear, discomfort, and panic symptoms $(p<0.001)$ was present. The $\mathrm{CO}_{2}$-induced increase in all self-report measures was strongly dose-dependent $(p<0.001$, except for fear and discomfort when comparing $9 \%$ to $0 \%: p=0.006$ and $p=0.015$, respectively) (Fig. 1 ). There was no effect of sex on self-report measures. The panic rates, defined as an increase of at least 25 in fear or discomfort in addition to an increase of at least four points on the panic symptom scale, were $46.67 \%$ and $67.5 \%$ for fear and discomfort, respectively.

\subsection{Effects of $\mathrm{CO}_{2}$ on cardiovascular measures}

A variety of outcome measures of the systolic and diastolic blood pressure as well as heart rate was analyzed in response to $0 \%, 9 \%$, $17.5 \%$, and $35 \% \mathrm{CO}_{2}$ (Supplement, Fig. 1, one subject for illustration). In general, with regard to both systolic and diastolic blood pressure, the AUC, peak and time needed to return to a stable level increased dose-dependently. In contrast, only minor effects of $\mathrm{CO}_{2}$ concentration on heart rate were observed. The results of the group means with regard to the AUC, peak, range, and proportion of subjects that did not recover as well as variation within a 60 s phase after the $\mathrm{CO}_{2}$ inhalation are presented in the following subsections. Women had a lower blood pressure after inhaling $0 \% \mathrm{CO}_{2}$. However, since the increases in response to $\mathrm{CO}_{2}$-enriched air were not statistically different between women and men, the physiological effects are not presented per sex. Analyses of carry-over effects did not indicate any significant effects.

\subsubsection{Systolic blood pressure}

Effects of increasing $\mathrm{CO}_{2}$ concentrations on group means of the systolic blood pressure over time (means per second) are depicted in Fig. 2 (top panel), showing that $\mathrm{CO}_{2}$ induced a brief drop in the first seconds, followed by a rise and another brief drop. Approximately $8 \mathrm{~s}$ after inhaling $\mathrm{CO}_{2}$ an abrupt rise occurred, reaching a peak, followed by quickly declining levels until stability was reached. These effects were dose-dependent until $17.5 \% \mathrm{CO}_{2}$. However, the time to return to a stable systolic blood pressure was longer in the $35 \% \mathrm{CO}_{2}$ condition in comparison with all other $\mathrm{CO}_{2}$ dosages.

Analysis of the derived cardiovascular outcomes (based on the 60 s recovery phase starting immediately after the second breath 
Table 1

Effects of increasing $\mathrm{CO}_{2}$ concentrations on the mean peak, range, and on the variation of the systolic as well as diastolic blood pressure and heart rate within the $60 \mathrm{~s}$ after the inhalation. Values represent means over the entire analyzed $60 \mathrm{~s}$ phase.

\begin{tabular}{lclcc}
\hline & $\% \mathrm{CO}_{2}$ & $\begin{array}{l}\text { Systolic blood } \\
\text { pressure }\end{array}$ & $\begin{array}{l}\text { Diastolic blood } \\
\text { pressure }\end{array}$ & Heart rate \\
\hline Peak & 0 & 135 & 83 & 109 \\
& 9 & 146 & 89 & 109 \\
& 17.5 & 156 & 97 & 108 \\
Range & 35 & 156 & 100 & 107 \\
& 0 & 44 & 32 & 43 \\
& 9 & 45 & 29 & 45 \\
Variation & 0 & 55 & 37 & 48 \\
& 95 & 57 & 42 & 0.23 \\
& 9 & 0.16 & -0.15 & 0.58 \\
& 17.5 & 0.39 & 0.11 & 0.78 \\
& 35 & 0.45 & 0.30 & 1.03 \\
\hline
\end{tabular}

of $\mathrm{CO}_{2}$ ) revealed a main effect of $\mathrm{CO}_{2}$ concentration on the systolic AUC $(p<0.001)$ and the $\mathrm{CO}_{2}$-induced peak $(p<0.001)$. The increase in the systolic AUC as well as the peak was dose-dependent until $17.5 \% \mathrm{CO}_{2}$, indicating reaching a plateau (see Table 1 for means and Table 2 for all $p$-values and effect sizes). Further, an overall effect of $\mathrm{CO}_{2}$ dosage was observed concerning the range of the systolic blood pressure $(p<0.001)$. Multiple comparisons revealed that $0 \%$ and $9 \%$, not different from one another $(p=0.833)$, induced a significantly smaller range than $17.5 \%$ (both $p<0.001$ ) and $35 \% \mathrm{CO}_{2}$ (both $p<0.001)$. The proportion of subjects who did not recover within 60 s after the $\mathrm{CO}_{2}$ inhalation was also dependent on the $\mathrm{CO}_{2}$ concentration (main effect $p<0.001$ ) (Supplement, Fig. 2, top panel, left). The highest proportions, i.e., the lowest number of subjects who did not recover within the $60 \mathrm{~s}$ time window, were observed after inhaling $17.5 \%$ and $35 \% \mathrm{CO}_{2}$ (Supplement, see Table 1 for means and Table 2 for $p$-values). Similarly to the previous analyses, a main effect of $\mathrm{CO}_{2}$ concentration on variation was observed $(p<0.001)$, with a relative increase in variation with increasing dosage of $\mathrm{CO}_{2}$ dosage.

\subsubsection{Diastolic blood pressure}

Effects of increasing $\mathrm{CO}_{2}$ concentrations on group means (per second) of the diastolic blood pressure are shown in Fig. 2 (middle panel). Similar to the systolic blood pressure, $\mathrm{CO}_{2}$ caused two brief declines within the first $8 \mathrm{~s}$, after which a steep dose-dependent rise eventually reaching a peak was observed. This was followed by a decrease until stable levels were reached. In addition, after inhaling $35 \% \mathrm{CO}_{2}$, it took longer to return to a stable level compared to lower $\mathrm{CO}_{2}$ concentrations.

Within the $60 \mathrm{~s}$ recovery phase after the double breath of $\mathrm{CO}_{2}$, an overall effect of $\mathrm{CO}_{2}$ concentration on the AUC of the diastolic blood pressure $(p<0.001)$ and on the $\mathrm{CO}_{2}$-elicited peak was observed $(p<0.001) . \mathrm{CO}_{2}$ caused a dose-dependent rise in the diastolic AUC and peak. However, with respect to the peak, a plateau was reached at $17.5 \% \mathrm{CO}_{2}$ (see Table 1 for means and Table 2 for $p$-values and effect sizes). A main effect of $\mathrm{CO}_{2}$ was also observed in the range of the diastolic blood pressure $(p<0.001)$, with an increase in the range when inhaling higher concentrations of $\mathrm{CO}_{2}$. In addition, all ranges differed significantly from one another. Further, analysis of the proportion of subjects that did not recover within $60 \mathrm{~s}$ after inhaling $\mathrm{CO}_{2}$ (overall effect $p<0.001$ ) revealed that most of the subjects did return to a stable diastolic blood pressure after inhaling $0 \%$ and $9 \% \mathrm{CO}_{2}$ (Supplement, Fig. 2, top panel, right). This proportion was strongly reduced after inhaling $17.5 \%$ and particularly $35 \% \mathrm{CO}_{2}$ (Supplement, see Table 1 for means and Table 2 for $p$-values). An overall effect of $\mathrm{CO}_{2}$ concentration was also present on the variation of the diastolic blood pressure $(p<0.001)$. The rise in variation showed a distinct dose-dependent pattern (all $p<0.001$ ).

\subsubsection{Heart rate}

Effects of increasing $\mathrm{CO}_{2}$ concentrations on mean heart rate before, during, and after the $\mathrm{CO}_{2}$ inhalation (mean per second) are illustrated in Fig. 2 (bottom panel). $\mathrm{CO}_{2}$ caused a brief rise for about $3 \mathrm{~s}$, followed by a drop and another, though slightly longer. rise after about 9-16 s. Subsequently, heart rate promptly returned to a stable level. In contrast to blood pressure, no dose-dependent relationship was present.

With regard to the analysis of the $60 \mathrm{~s}$ phase after inhaling $\mathrm{CO}_{2}$, the observed main effect of $\mathrm{CO}_{2}$ concentration on the AUC of the heart rate was highly significant $(p<0.001)$. Interestingly, inhaling $17.5 \% \mathrm{CO}_{2}$ showed the smallest AUC compared to all other $\mathrm{CO}_{2}$ concentrations (see Table 1 for means and Table 2 for $p$-values and effect sizes). No significant overall effect regarding a $\mathrm{CO}_{2}$-elicited heart rate peak was present. With respect to the

Table 2

Effects of increasing $\mathrm{CO}_{2}$ concentrations on the mean AUC, peak, range, proportion who did not recover, and variation of the systolic and diastolic blood pressure and heart rate within the $60 \mathrm{~s}$ phase after the inhalation. Values represent p-values (pairwise comparisons using Holm's method, corrected for multiple testing) or effect sizes (Cohen's $d$, standardized mean gains; bold).

\begin{tabular}{|c|c|c|c|c|c|c|c|c|c|c|c|c|}
\hline & \multicolumn{4}{|c|}{ Systolic blood pressure } & \multicolumn{4}{|c|}{ Diastolic blood pressure } & \multicolumn{4}{|c|}{ Heart rate } \\
\hline \multicolumn{13}{|l|}{ AUC } \\
\hline$\% \mathrm{CO}_{2}$ & 0 & 9 & 17.5 & 35 & 0 & 9 & 17.5 & 35 & 0 & 9 & 17.5 & 35 \\
\hline 0 & - & 0.41 & 0.71 & 0.88 & - & 0.44 & 0.75 & 1.00 & - & -0.14 & -0.43 & -0.2 \\
\hline 9 & 0.002 & - & 0.26 & 0.4 & $<0.001$ & - & 0.26 & 0.46 & 0.211 & - & -0.29 & -0.06 \\
\hline 17.5 & $<0.001$ & 0.026 & - & 0.14 & $<0.001$ & 0.014 & - & 0.21 & $<0.001$ & 0.002 & - & 0.25 \\
\hline 35 & $<0.001$ & 0.005 & 0.187 & - & $<0.001$ & $<0.001$ & 0.027 & - & 0.105 & 0.552 & 0.016 & - \\
\hline \multicolumn{13}{|l|}{ Peak } \\
\hline 0 & - & 0.65 & 1.2 & 1.21 & - & 0.57 & 1.44 & 1.72 & - & 0.04 & -0.07 & -0.08 \\
\hline 9 & $<0.001$ & - & 0.44 & 0.45 & $<0.001$ & - & 0.66 & 0.88 & 1.000 & - & -0.11 & -0.13 \\
\hline 17.5 & $<0.001$ & $<0.001$ & - & 0.01 & $<0.001$ & $<0.001$ & - & 0.19 & 1.000 & 0.736 & - & -0.01 \\
\hline 35 & $<0.001$ & 0.003 & 0.912 & - & $<0.001$ & $<0.001$ & 0.092 & - & 1.000 & 1.000 & 1.000 & - \\
\hline \multicolumn{13}{|l|}{ Range } \\
\hline 0 & - & 0.09 & 0.77 & 0.88 & - & -0.35 & 0.61 & 1.12 & - & 0.19 & 0.38 & 0.46 \\
\hline 9 & 0.833 & - & 0.63 & 0.73 & 0.002 & - & 0.51 & 1.04 & 0.133 & - & 0.19 & 0.26 \\
\hline 17.5 & $<0.001$ & $<0.001$ & - & 0.1 & $<0.001$ & $<0.001$ & - & 0.44 & $<0.001$ & 0.133 & - & 0.07 \\
\hline 35 & $<0.001$ & $<0.001$ & 0.833 & - & $<0.001$ & $<0.001$ & 0.002 & - & 0.001 & 0.133 & 0.511 & - \\
\hline \multicolumn{13}{|c|}{ Variation } \\
\hline 0 & - & 0.75 & 0.92 & 1.49 & - & 0.66 & 1.15 & 1.67 & - & 0.65 & 1.03 & 1.5 \\
\hline 9 & $<0.001$ & - & 0.13 & 0.55 & $<0.001$ & - & 0.51 & 1.04 & $<0.001$ & - & 0.41 & 0.91 \\
\hline 17.5 & $<0.001$ & 0.251 & - & 0.46 & $<0.001$ & $<0.001$ & - & 0.44 & $<0.001$ & $<0.001$ & - & 0.53 \\
\hline 35 & $<0.001$ & $<0.001$ & $<0.001$ & - & $<0.001$ & $<0.001$ & $<0.001$ & - & $<0.001$ & $<0.001$ & $<0.001$ & - \\
\hline
\end{tabular}




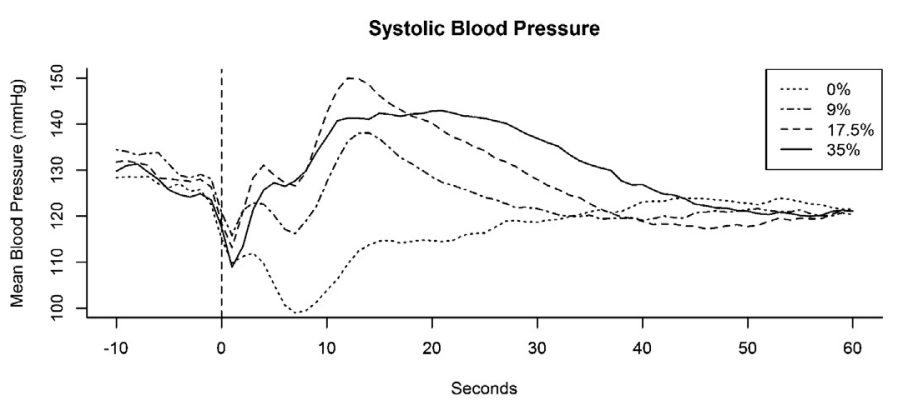

Diastolic Blood Pressure
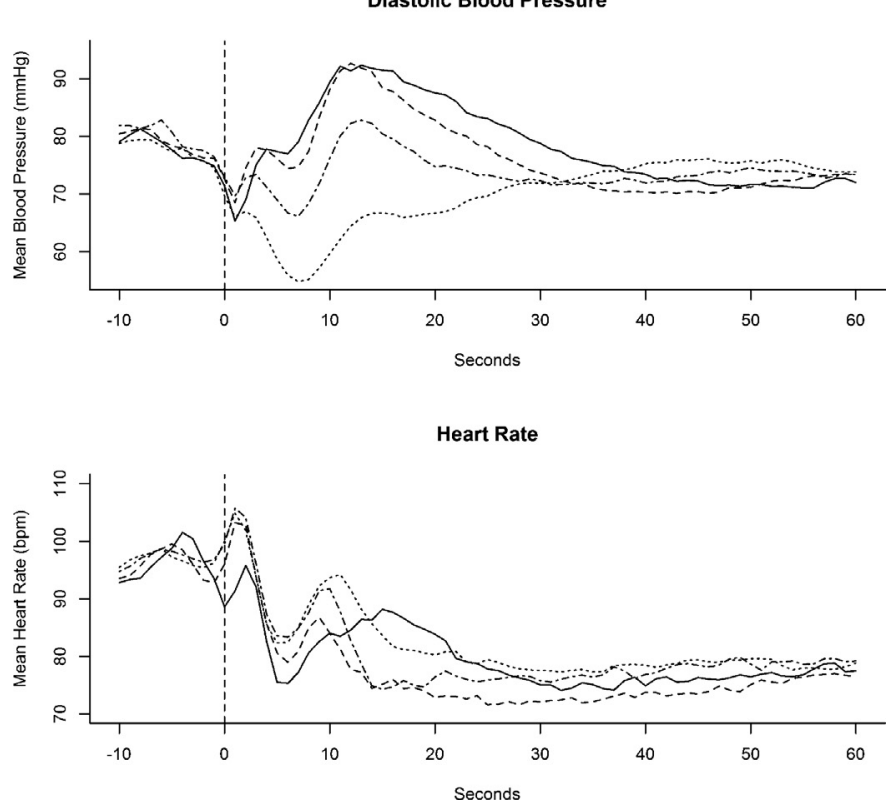

Fig. 2. Effects of increasing concentrations of $\mathrm{CO}_{2}$ on mean systolic blood pressure (top panel), diastolic blood pressure (middle panel), and heart rate (bottom panel) over time (means per second). The dashed line indicates the end of a double breath of $\mathrm{CO}_{2}$. Top panel: Inhaling $\mathrm{CO}_{2}$ induced two brief decreases in systolic blood pressure, after which a rise could be observed, followed by a recovery phase in which the blood pressure returned to stable levels. The effect of $\mathrm{CO}_{2}$ was dose-dependently, with the exception of $35 \% \mathrm{CO}_{2}$, which caused a lower systolic blood pressure peak than $17.5 \% \mathrm{CO}_{2}$. However, at $35 \%$, the systolic blood pressure took longer to return to a stable level compared to the other $\mathrm{CO}_{2}$ concentrations. Middle panel: $\mathrm{CO}_{2}$ induced two short decreases in diastolic blood pressure, after which the levels increased dose-dependently until reaching a peak, similar to the systolic blood pressure. Subsequently, the diastolic blood pressure decreased again, eventually reaching stable levels again. Bottom panel: $\mathrm{CO}_{2}$ induced a short steep rise in mean heart rate, after which a drop, followed by second, longer rise could be observed. Subsequently, heart rate quickly returned to a stable level. $\mathrm{CO}_{2}$-induced alterations in heart rate were not dose-dependent.

range of the heart rate, a main effect of $\mathrm{CO}_{2}$ dosage was observed $(p<0.001)$. Pairwise comparisons using Holm's method revealed that inhalation of the two highest $\mathrm{CO}_{2}$ concentrations, i.e., $17.5 \%$ and $35 \%$, was associated with an increased range compared to $0 \% \mathrm{CO}_{2}(p<0.001$ and $p=0.001$, respectively). A main effect was also present regarding the proportion of subjects that did not recover within $60 \mathrm{~s}$ after the inhalation $(p=0.001)$ (Supplement, Fig. 2, bottom panel), indicating that all $\mathrm{CO}_{2}$ concentrations resulted in a larger proportion compared to the $0 \%$ condition (Supplement, see Table 1 for means and Table 2 for $p$-values). Furthermore, an overall effect of $\mathrm{CO}_{2}$ dosage on heart rate variation was found $(p<0.001)$, with a dose-dependent rise in variation. Effects of all $\mathrm{CO}_{2}$ dosages differed significantly from one another (all $p<0.001$ ).
Table 3

Correlations (represented as $R$-values) and corresponding $p$-values (permutation test) between mean change in fear (VAS-F), discomfort (VAS-D), and panic symptoms (PSL) and the outcome measures of the diastolic cardiovascular outcome measures as well as heart rate.

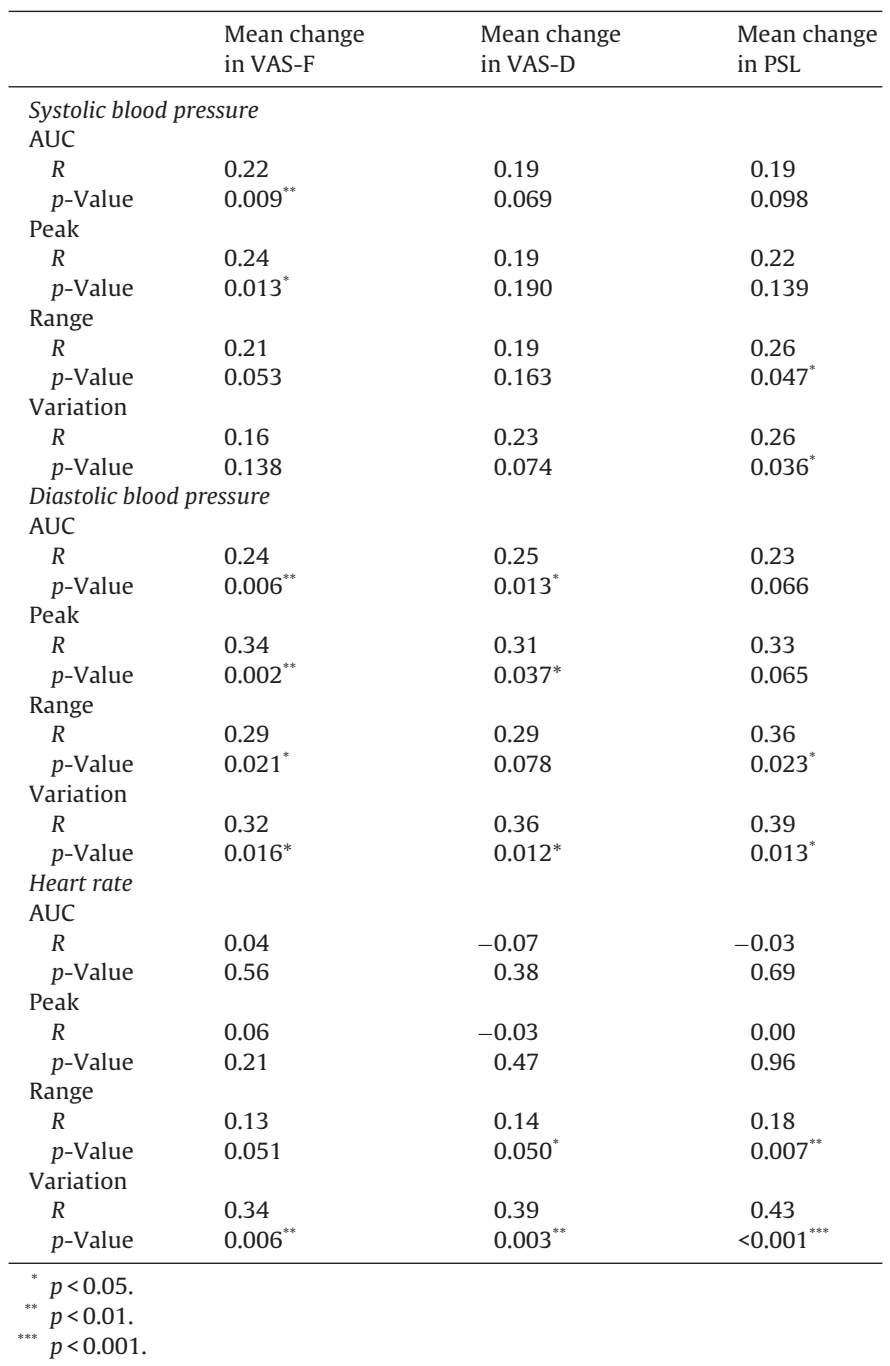

\subsection{Correlation analyses between self-reports and cardiovascular outcomes}

Correlation analyses between the change in fear, discomfort, and panic symptoms, and the cardiovascular outcomes revealed several significant correlations (see Table 3 for an overview). Both the AUC and the peak of the systolic blood pressure were significantly correlated with fear only $(R=0.22, p=0.009$ and $R=0.24, p=0.013$, respectively). The range as well as the variation in systolic blood pressure was correlated with panic symptoms $(R=0.26, p=0.047$ and $R=0.26, p=0.036$, respectively). Additionally, all outcomes of the diastolic blood pressure were significantly correlated with fear, in particular the AUC and the peak diastolic blood pressure ( $R=0.24, p=0.006$ and $R=0.34, p=0.002$, respectively). Moreover, most outcomes of the diastolic blood pressure also correlated with discomfort. With regard to heart rate, strong correlations were found between the heart rate variation and fear $(R=0.34, p=0.006)$, discomfort $(R=0.39, p=0.003)$, as well as panic symptoms $(R=0.43$, $p<0.001)$. 


\section{Discussion}

In the present study we aimed to describe the emotional and cardiovascular effects provoked by four different concentrations of $\mathrm{CO}_{2}$, ranging from $0 \%$ (room air) to $35 \% \mathrm{CO}_{2}$, in a large sample of healthy volunteers. In addition to replicating a dose-dependent fear response to $\mathrm{CO}_{2}$, we substantially extended our previous studies by including continuous monitoring of cardiovascular effects. The results show $\mathrm{CO}_{2}$-induced increases in most outcomes of the blood pressure, with highest discriminability for the diastolic blood pressure. Heart rate was mainly affected in terms of variation. Correlation analyses revealed a significant relationship between fear and heart rate variation as well as several outcome measures of the diastolic blood pressure.

\subsection{Effects of $\mathrm{CO}_{2}$ on self-reports}

$\mathrm{CO}_{2}$ proved to provoke an immediate dose-dependent increase of fear, discomfort, and panic symptoms. This observation is consistent with previous studies by our group, demonstrating that increasing concentrations of $\mathrm{CO}_{2}$ are associated with increased negative affect in healthy subjects. Particularly $35 \% \mathrm{CO}_{2}$ has been shown to be an effective dosage to induce the emotions and symptoms associated with naturally occurring PAs in PD patients, conforming to the DSM-IV criteria for PAs (Griez et al., 2007; Schruers et al., 2011). In this respect, this study corroborates the use of $\mathrm{CO}_{2}$ as a reliable, fast, and relatively simple laboratory model for PAs.

Further, no sex differences were found. This result diverges from epidemiological data showing that women are more often affected by PD than men (Dick, Bland, \& Newman, 1994; Gater et al., 1998). Previous research failed to show consistent results with regard to sex differences in $\mathrm{CO}_{2}$-reactivity. While some research groups did report more fear and panic (Kelly, Forsyth, \& Karekla, 2006), stronger increases in anxiety (Bunaciu, Feldner, Babson, Zvolensky, \& Eifert, 2012) or higher levels of panic symptoms (Nillni et al., 2012) in women compared to men, others did not find a sex effect (Griez et al., 2007; Nardi et al., 2007; Perna, Caldirola, et al., 2004; Poonai et al., 2000). It has been proposed that environmental factors such as socializing may prime women to be more likely to report distress, whilst fearful behavior may be less accepted in men (McLean \& Anderson, 2009). Other factors such as anxiety sensitivity (Schmidt \& Zvolensky, 2007), which were not assessed in the present study, may also play a confounding role.

\subsection{Effects of $\mathrm{CO}_{2}$ on cardiovascular outcomes}

In the present study, an immediate activation of the autonomic nervous system in response to $\mathrm{CO}_{2}$ was observed, with a rapid increase in both systolic and diastolic blood pressure. Except for variation, the outcome measures of the systolic blood pressure showed no statistical difference between $17.5 \%$ and $35 \% \mathrm{CO}_{2}$, though subjective emotions and panic symptoms increased dosedependently, which was well mimicked by the diastolic blood pressure. These diverging results may be explained by a ceiling effect in the case of the systolic blood pressure. Further, these observations also imply that diastolic blood pressure has a better discriminability and higher sensitivity compared to systolic blood pressure and is therefore preferable in analyzing the reactivity to $\mathrm{CO}_{2}$. Notably, no carry-over effects were present for any outcome measure, implying that the effects of the $\mathrm{CO}_{2}$ concentrations were not affected by the order given.

Since this is the first study that assessed both the emotional and cardiovascular response to $0 \%, 9 \%, 17.5 \%$, and $35 \% \mathrm{CO}_{2}$, and analyzed a variety of physiological outcomes, we are unable to directly compare these outcome measures with previous studies. However, general effects of $\mathrm{CO}_{2}$ inhalations have been described previously. The $35 \% \mathrm{CO}_{2}$-induced rise in systolic blood pressure is consistent with previous studies (Argyropoulos et al., 2002; Griez \& Van den Hout, 1983; Kaye et al., 2004; Kaye, Young, Mathias, Watson, \& Lightman, 2006; Richey et al., 2010; Shufflebotham et al., 2009; Wetherell et al., 2006). With regard to the diastolic blood pressure, an immediate $\mathrm{CO}_{2}$-induced increase has also been reported previously in some (Griez \& Van den Hout, 1983; Kaye et al., 2006; Richey et al., 2010), but not all studies (Argyropoulos et al., 2002; Bailey et al., 2005; Bailey, Papadopoulos, Lingford-Hughes, \& Nutt, 2007; Kaye et al., 2004; Papadopoulos et al., 2010). The discrepancies between our results and those of other studies might be explained by differential methodology. For instance, a single vital capacity breath of $35 \% \mathrm{CO}_{2}$ (Argyropoulos et al., 2002; Kaye et al., 2004), in contrast to a double vital capacity breath in the present study, exposure to lower $\mathrm{CO}_{2}$ concentrations such as $7.5 \%$ for $20 \mathrm{~min}$ (Bailey et al., 2005, 2007; Papadopoulos et al., 2010), and differences in terms of sample size (Argyropoulos et al., 2002; Bailey et al., 2005), as well as methods of analysis (Gorman et al., 1990) can contribute to varying results. In comparison with these other studies the present study has several advantages. Since it has been shown that in healthy volunteers specifically a double breath of $35 \%$ $\mathrm{CO}_{2}$ provokes emotions and panic symptoms resembling a real-life PA (Griez et al., 2007; Schruers et al., 2011), our approach may be seen as more robust to induce a panic response with a rapid onset. Moreover, our large sample size on top of measuring the effects of four concentrations of $\mathrm{CO}_{2}$ in each subject presumably yielded more reliable results. In addition, analytical methods such as calculating averages over $15 \mathrm{~s}$ intervals (Gorman et al., 1990) can mask small and brief fluctuations, resulting in a possibly inappropriate interpretation of the results. This emphasizes the need for continuous monitoring and analysis of the data obtained in short time frame such as twice per second as in the present study.

With regard to heart rate, contrary to our hypothesis, the outcome measures did not increase in a dose-dependent manner and were, in general, hardly affected by any $\mathrm{CO}_{2}$ concentration. More specifically, the AUC of the heart rate decreased with increasing $\mathrm{CO}_{2}$ concentration, with the strongest effect in the $17.5 \% \mathrm{CO}_{2}$ condition. This effect might be compensatory to the increased blood pressure and was also observed in previous studies using a single (Argyropoulos et al., 2002; Kaye et al., 2004; Shufflebotham et al., 2009; Wetherell et al., 2006) and a double vital breath of 35\% $\mathrm{CO}_{2}$ (Verschoor \& Markus, 2011). However, other studies reported an increase in heart rate (Bailey et al., 2005; Poonai et al., 2000; Richey et al., 2010; Sasaki et al., 1996) or did not find any effect (Bailey et al., 2007; Bystritsky \& Shapiro, 1992). These discrepancies may be again explained by differential methodology as previously described. Interestingly, a clear dose-dependent increase in the heart rate variation was observed, i.e., the level of heart rate fluctuations increased with a rising dosage of $\mathrm{CO}_{2}$. This observation suggests that panic symptoms such as palpitations may be more related to fluctuations in heart rate rather than to a mere increase in frequency.

In the present study, the increases in blood pressure and heart rate were comparable in men and women in all $\mathrm{CO}_{2}$-enriched air conditions. Similarly, Kelly et al. (2006) failed to reliably discriminate between men and women when assessing the response to 12 inhalations of $20 \% \mathrm{CO}_{2}$ for $20 \mathrm{~s}$. However, this result is not uniform as some other studies did report sex differences in the physiological response to inhaling $\mathrm{CO}_{2}$. For instance, in a recent study by Nillni et al. (2012), when administering $10 \% \mathrm{CO}_{2}$ for $4 \mathrm{~min}$, women had higher heart rate levels during the inhalation when compared to men, an effect which could not be attributed to baseline differences in heart rate. This result is in line with a previous study using the same concentration of $\mathrm{CO}_{2}$ and administration time (Gregor \& Zvolensky, 2008). Taken together, future research should 
further clarify whether women are more physiologically reactive to laboratory-induced PAs than men.

\subsection{Correlations between self-reports and cardiovascular outcome measures}

Correlation analyses between self-report measures and cardiovascular outcomes revealed the most significant relationship between fear and heart rate variation. As previously mentioned, this observation may imply that fluctuations caused by a homeostatic disturbance play a more important role in $\mathrm{CO}_{2}$-induced fear than, e.g., an increase in heart rate itself. In addition to heart rate, fear and discomfort were associated with most of the outcomes of the diastolic blood pressure, particularly the AUC and the $\mathrm{CO}_{2}$ induced peak. Correlation analysis of a previous study by Bailey et al. (2003) did not reveal any relationship between blood pressure or heart rate and fear. Evidently, analyzing several outcome measures such as the AUC, peak, and variation in distinct cardiovascular parameters in a temporal manner gives a more detailed view into the complex relationship between physiology and panic, thereby revealing correlations that might not be detected when focusing on, for instance, the mean blood pressure and heart rate alone.

Regarding the systolic blood pressure, fewer correlations with self-reports were present. This result, in combination with the observation that the diastolic blood pressure mimicked the degree of fear, discomfort, and panic symptoms, suggests that the diastolic blood pressure is the most favorable parameter to assess the physiological response to $\mathrm{CO}_{2}$.

\subsection{Limitations}

Various factors are known to have a potential influence on the individual response to inhaling $\mathrm{CO}_{2}$. In the present study, several confounding effects were minimized using strict exclusion criteria. For instance, heavy smokers (Abrams et al., 2008; Knuts et al., 2010), alcohol users (Cosci et al., 2005; Kushner et al., 1996) and users of drugs/medications that are considered to have an effect on the nervous or cardiovascular system were excluded during the screening procedure. In addition, subjects were instructed to refrain from coffee on all test days to avoid possible anxiogenic effects of caffeine (Nardi et al., 2007; Vilarim et al., 2011). However, other potential confounders such as anxiety sensitivity (Blechert et al., 2013; Schmidt \& Zvolensky, 2007) and physical activity (Esquivel et al., 2012; Smits et al., 2009) were not assessed. Moreover, due to practical reasons, we also did not control for menstrual cycle phase (Perna, Brambilla, Arancio, \& Bellodi, 1995). Including those measurements would improve the study design and may increase the reliability of the results.

\subsection{Panic as an instance of a primal emotion}

We have previously proposed (in line with Denton, 2006; Denton et al., 2009) that PAs are the expression of a primal emotion (Colasanti et al., 2012). The interoceptor-driven sensation of a bodily disturbance linked to immediate threat of the individual leads to a compelling intention (i.e., adaptive homeostatic response) to protect the individual against that vital threat. In accordance with this notion, we showed in the present study that self-reports, representing sensations that emerge into consciousness, and the physiological response to $\mathrm{CO}_{2}$ are closely related. The present results are in accordance with previous data showing that neuronal activation of (para)limbic brain areas and deactivation of other areas in response to $\mathrm{CO}_{2}$ are congruent with the pattern observed with a subjective experience of other primal emotions such as extreme thirst, hunger or pain (Liotti et al., 2001). Together, the close relationship of self-reports and physiology in the present study as well as the congruency of (de)activation of brain structures in response to $\mathrm{CO}_{2}$ in other primal emotions supports our proposition that PAs are an instance of a primal emotion.

\subsection{Clinical implications and future perspectives}

The symptoms experienced during a PA such as palpitations, chest pain, breathing difficulties, and dizziness are not specific or automatically attributable to a PA. Up to $20 \%$ of patients suffering from chest pain and seeking help in emergency departments meet the official criteria for PD (Huffman \& Pollack, 2003). This observation emphasizes the need for a fast and refined assessment of PAs.

In the present study, the overall heart rate response to inhaling $\mathrm{CO}_{2}$ was not strongly affected. The variation in heart rate, however, increased dose-dependently. This may indicate that panic symptoms such as palpitations are associated with heart rate fluctuations (i.e., brief disturbances in the homeostasis) rather than, for instance, a mere increase in frequency. Furthermore, among the assessed cardiovascular parameters, the diastolic blood pressure appears to be the most sensitive and robust measure, deeming it a putative biomarker for (experimentally induced) panic. Therefore, we propose that diastolic blood pressure measurements should be included in future studies to complement other measures such as self-reports.

It has been previously demonstrated that $\mathrm{CO}_{2}$ inhalation is a reliable technique to provoke intense, but transient, fear and/or discomfort and various sensations in PD patients as well as healthy subjects. These sensations closely resemble the symptomatology of real-life PAs. In PD patients, a single vital capacity breath of $35 \% \mathrm{CO}_{2}$ is sufficient, whereas in healthy subjects, a double breath of $35 \% \mathrm{CO}_{2}$ is particularly effective in triggering those symptoms. These observations suggest the existence of a $\mathrm{CO}_{2}$-reactivity continuum based on a common mechanism, thereby opening the possibility of referring to healthy subjects for the study of panic, which has several advantages. First, patients do not need to be burdened unnecessarily. Second, the potency of new therapies to modulate the response to $\mathrm{CO}_{2}$ can also be evaluated in healthy volunteers before eventually testing promising interventions in patients with PD. Third, sampling and testing healthy volunteers provides insights into the fundamental mechanisms underlying $\mathrm{CO}_{2}$-reactivity and panic, without possible masking effects of comorbidity and medication.

Bouton, Mineka, and Barlow (2001) proposed that conditioned anxiety about future PAs in response to extero- or interoceptive cues is a key process in the progression of PAs into PD. This process can also be best modeled in healthy subjects, because PD patients have progressed beyond the initial conditioning. Experimentally, the use of interoceptive cues is challenging given their internal nature. As inhaling $35 \% \mathrm{CO}_{2}$ reliably causes an immediate intense emotional response, we recently used $\mathrm{CO}_{2}$ inhalation as unconditioned stimulus to examine selective interoceptive conditioning (De Cort, Griez, Buchler, \& Schruers, 2012). In that study, we showed that $\mathrm{CO}_{2}$ may be a valuable agent for establishing an effective interoceptive cue in conditioning research. This is particularly interesting to investigate the role of interoceptive conditioning in the development from spontaneous PAs to PD. In future studies, it would be therefore worthwhile to also study patients with anxiety disorders to examine the difference between the adaptive nature of fear conditioning and the dysfunctional nature of anxiety disorders (Beckers, Krypotos, Boddez, Effting, \& Kindt, 2013).

Furthermore, the use of $\mathrm{CO}_{2}$ as an interoceptive cue may be a promising technique in the treatment of $\mathrm{PD}$. In spite of its effectiveness (Sanchez-Meca, Rosa-Alcazar, Marin-Martinez, \& Gomez-Conesa, 2010), interoceptive exposure is not yet commonly used in daily practice. When it is included in therapy, symptom 
induction exercises such as hyperventilation or spinning are most often used. However, these exercises only induce a fraction of the panic symptoms (Antony, Ledley, Liss, \& Swinson, 2006; Lee et al., 2006). Therefore, we propose to include $35 \% \mathrm{CO}_{2}$ inhalation in interoceptive exposure therapy. The congruency with naturally occurring PAs will putatively increase the learning of how to deal with future PAs and thereby improve the effectiveness of cognitive behavioral therapies.

While $\mathrm{CO}_{2}$ inhalation in humans is a well-established experimental model for panic and increased the knowledge about that psychobiological phenomenon, it is limited in its potential to contribute to molecular insights. These can be better assessed in animal research. In a recent rodent study (Ziemann et al., 2009), it was shown that exposure to $\mathrm{CO}_{2}$ also triggers fear behavior in mice. Various techniques were used to provide a molecular substrate for this effect. It was demonstrated that the fear response is dependent on the $\mathrm{pH}$-sensitive ion channel ASIC1a located within the amygdala. More specifically, $\mathrm{CO}_{2}$ reduces the $\mathrm{pH}$ within the amygdala, thereby stimulating amygdalar ASIC1a and triggering fear behavior. Knockout of the gene encoding ASIC1 1 a blunted this particular effect. Main outcome measures in this study were a series of behavioral tests. In order to be relevant for translation into a human perspective, animal studies should ideally use stimuli and outcome measures that are as similar as possible to those of human studies. In most human panic provocation studies, symptom reports are used as outcome. It is obvious that observed behavior in animals and symptom reports in humans are not interchangeable. Physiology, however, is measurable in both rodents and humans, which makes it a valuable addition to assess the response to $\mathrm{CO}_{2}$ in different species. We therefore propose to extend the methods from the present study to animal studies, where physiological outcome measures are not yet commonly used. Thereby, the comparability between animal and human research can be considerably improved, thus contributing to a better translation of knowledge gained in the laboratory back to the clinic.

\subsection{Conclusion}

In sum, the present study addressed identifiable shortcomings in previous studies such as small sample sizes, and methodological as well as technical limitations, to comprehensively investigate the reactivity to $\mathrm{CO}_{2}$ in healthy volunteers. The results show a dosedependent subjective emotional and panic symptom response to $\mathrm{CO}_{2}$. This pattern was best represented by the diastolic blood pressure, indicating a better sensitivity and discriminability compared to the systolic blood pressure and heart rate. Further, particularly significant correlations were found between self-reports and heart rate variation as well as several outcome measures of the diastolic blood pressure. These results indicate that the combination of both subjective self-reports and cardiovascular measures is a promising method to obtain a more refined and reliable assessment of PAs and to assess PAs in all its aspects as an instance of a primal emotion. Particularly the diastolic blood pressure appears to be a robust and putative biomarker to assess the reactivity to $\mathrm{CO}_{2}$ in future studies.

\section{Conflict of interest}

The authors declare no conflict of interest.

\section{Appendix A. Supplementary data}

Supplementary data associated with this article can be found, in the online version, at http://dx.doi.org/10.1016/j.biopsycho.2013. 06.004 .

\section{References}

Abrams, K., Zvolensky, M. J., Dorflinger, L., Galatis, A., Blank, M., \& Eissenberg, T. (2008). Fear reactivity to bodily sensations among heavy smokers and nonsmokers. Experimental and Clinical Psychopharmacology, 16, 230-239.

American Psychiatric Association. (2000). Diagnostic and Statistical Manual of Mental Disorders: DSM-IV-TR (4th ed.). Washington, DC: American Psychiatric Association.

Andlin-Sobocki, P., \& Wittchen, H. U. (2005). Cost of anxiety disorders in Europe European Journal of Neurology, 12(Suppl. 1), 39-44.

Antony, M. M., Ledley, D. R., Liss, A., \& Swinson, R. P. (2006). Responses to symptom induction exercises in panic disorder. Behaviour Research and Therapy, 44, 85-98.

Argyropoulos, S. V., Bailey, J. E., Hood, S. D., Kendrick, A. H., Rich, A. S., Laszlo, G., et al (2002). Inhalation of $35 \% \mathrm{CO}(2)$ results in activation of the HPA axis in healthy volunteers. Psychoneuroendocrinology, 27, 715-729.

Bailey, J. E., Argyropoulos, S. V., Kendrick, A. H., \& Nutt, D. J. (2005). Behavioral and cardiovascular effects of $7.5 \% \mathrm{CO}_{2}$ in human volunteers. Depression and Anxiety, $21,18-25$.

Bailey, J. E., Argyropoulos, S. V., Lightman, S. L., \& Nutt, D. J. (2003). Does the brain noradrenaline network mediate the effects of the $\mathrm{CO}_{2}$ challenge. Journal of Psychopharmacology, 17, 252-259.

Bailey, J. E., Papadopoulos, A., Lingford-Hughes, A., \& Nutt, D. J. (2007). D-Cycloserine and performance under different states of anxiety in healthy volunteers. Psychopharmacology, 193, 579-585.

Becker, B. J. (1988). Synthesizing standardized mean-change measures. British Journal of Mathematical and Statistical Psychology, 41, 257-278.

Beckers, T., Krypotos, A. M., Boddez, Y., Effting, M., \& Kindt, M. (2013). What's wrong with fear conditioning? Biological Psychology, 92, 90-96.

Blechert, J., Wilhelm, F. H., Meuret, A. E., Wilhelm, E. M., \& Roth, W. T. (2010). Respiratory, autonomic, and experiential responses to repeated inhalations of $20 \% \mathrm{CO}(2)$ enriched air in panic disorder, social phobia, and healthy controls. Biological Psychology, 84, 104-111.

Blechert, J., Wilhelm, F. H., Meuret, A. E., Wilhelm, E. M., \& Roth, W. T. (2013). Experiential, autonomic, and respiratory correlates of $\mathrm{CO}_{2}$ reactivity in individuals with high and low anxiety sensitivity. Psychiatry Research,. S0165-1781(13)00082-6 [epub ahead of print]

Bouton, M. E., Mineka, S., \& Barlow, D. H. (2001). A modern learning theory perspective on the etiology of panic disorder. Psychological Review, 108, 4-32.

Bradley, S. R., Pieribone, V. A., Wang, W., Severson, C. A., Jacobs, R. A., \& Richerson, G. B. (2002). Chemosensitive serotonergic neurons are closely associated with large medullary arteries. Nature Neuroscience, 5, 401-402.

Bunaciu, L., Feldner, M. T., Babson, K. A., Zvolensky, M. J., \& Eifert, G. H. (2012). Biological sex and panic-relevant anxious reactivity to abrupt increases in bodily arousal as a function of biological challenge intensity. Journal of Behavior Therapy and Experimental Psychiatry, 43, 526-531.

Bystritsky, A., Craske, M., Maidenberg, E., Vapnik, T., \& Shapiro, D. (2000). Autonomic reactivity of panic patients during a $\mathrm{CO}_{2}$ inhalation procedure. Depression and Anxiety, 11, 15-26.

Bystritsky, A., \& Shapiro, D. (1992). Continuous physiological changes and subjective reports in panic patients: A preliminary methodological report. Biological Psychiatry, 32, 766-777.

Cleveland, W. S., \& Devlin, S. J. (1988). Locally weighted regression: An approach to regression analysis by local fitting. Journal of the American Statistical Association, 83, 596-610.

Colasanti, A., Esquivel, G., Schruers, K. J., \& Griez, E. J. (2012). On the psychotropic effects of carbon dioxide. Current Pharmaceutical Design, 18, 5627-5637.

Colasanti, A., Salamon, E., Schruers, K., van Diest, R., van Duinen, M., \& Griez, E. J. (2008). Carbon dioxide-induced emotion and respiratory symptoms in healthy volunteers. Neuropsychopharmacology, 33, 3103-3110.

Corcoran, A. E. Hodges, M. R., Wu, Y., Wang, W., Wylie, C. J., Deneris, E. S., et al. (2009). Medullary serotonin neurons and central $\mathrm{CO}_{2}$ chemoreception. Respiratory Physiology \& Neurobiology, 168, 49-58.

Cosci, F., De Gooyer, T., Schruers, K., Faravelli, C., \& Griez, E. (2005). The influence of ethanol infusion on the effects of $35 \% \mathrm{CO}_{2}$ challenge. A study in panic disorder patients and healthy volunteers. European Psychiatry, 20, 299-303.

De Cort, K., Griez, E., Buchler, M., \& Schruers, K. (2012). The role of interoceptive fear conditioning in the development of panic disorder. Behavior Therapy, 43, 203-215.

Denton, D. (2006). The primordial emotions: The dawning of consciousness. Oxford University Press.

Denton, D. A., McKinley, M. J., Farrell, M., \& Egan, G. F. (2009). The role of primordial emotions in the evolutionary origin of consciousness. Consciousness and Cognition, 18, 500-514.

Dick, C. L., Bland, R. C., \& Newman, S. C. (1994). Epidemiology of psychiatric disorders in Edmonton Panic disorder. Acta Psychiatrica Scandinavica. Supplementum, 376 45-53.

Esquivel, G., Dandachi, A., Knuts, I., Goossens, L., Griez, E., \& Schruers, K. (2012) Effects of acute exercise on $\mathrm{CO}(2)$-induced fear. Depression and Anxiety, 29, $155-158$

Esquivel, G., Schruers, K., \& Griez, E. (2008). Experimental models: Panic and fear. In R. J. Blanchard, G. Griebel, \& D. J. Nutt (Eds.), Handbook of anxiety and fear (pp. 413-435). Amsterdam: Elsevier BV.

Esquivel, G., Schruers, K. R., Maddock, R. J., Colasanti, A., \& Griez, E. J. (2010). Acids in the brain: A factor in panic. Journal of Psychopharmacology, 24, 639-647.

Gater, R., Tansella, M., Korten, A., Tiemens, B. G., Mavreas, V. G., \& Olatawura, M. O. (1998). Sex differences in the prevalence and detection of depressive and 
anxiety disorders in general health care settings: Report from the World Health Organization Collaborative Study on Psychological Problems in General Health Care. Archives of General Psychiatry, 55, 405-413.

Gorman, J. M., Kent, J., Martinez, J., Browne, S., Coplan, J., \& Papp, L. A. (2001). Physiological changes during carbon dioxide inhalation in patients with panic disorder, major depression, and premenstrual dysphoric disorder: Evidence for a central fear mechanism. Archives of General Psychiatry, 58, 125-131.

Gorman, J. M., Papp, L. A., Martinez, J., Goetz, R. R., Hollander, E., Liebowitz, M. R., et al. (1990). High-dose carbon dioxide challenge test in anxiety disorder patients. Biological Psychiatry, 28, 743-757.

Gregor, K. L., \& Zvolensky, M. J. (2008). Anxiety sensitivity and perceived control over anxiety-related events: Evaluating the singular and interactive effects in the prediction of anxious and fearful responding to bodily sensations. Behaviour Research and Therapy, 46, 1017-1025.

Griez, E., \& Van den Hout, M. A. (1983). Carbon dioxide and anxiety: Cardiovascular effects of a single inhalation. Journal of Behavior Therapy and Experimental Psychiatry, 14, 297-304.

Griez, E. J., Colasanti, A., van Diest, R., Salamon, E., \& Schruers, K. (2007). Carbon dioxide inhalation induces dose-dependent and age-related negative affectivity. PLoS ONE, 2, e987.

Holm, S. (1979). A simple sequentially rejective multiple test procedure. Scandinavian Journal of Statistics, 6, 65-70.

Huffman, J. C., \& Pollack, M. H. (2003). Predicting panic disorder among patients with chest pain: An analysis of the literature. Psychosomatics, 44, 222-236.

Kaye, J., Buchanan, F., Kendrick, A., Johnson, P., Lowry, C., Bailey, J., et al. (2004). Acute carbon dioxide exposure in healthy adults: Evaluation of a novel means of investigating the stress response. Journal of Neuroendocrinology, 16, 256-264.

Kaye, J. M., Young, T. M., Mathias, C. J., Watson, L., \& Lightman, S. L. (2006). Neuroendocrine and behavioural responses to $\mathrm{CO}_{2}$ inhalation in central versus peripheral autonomic failure. Clinical Autonomic Research, 16, 121-129.

Kelly, M. M., Forsyth, J. P., \& Karekla, M. (2006). Sex differences in response to a panicogenic challenge procedure: An experimental evaluation of panic vulnerability in a non-clinical sample. Behaviour Research and Therapy, 44, 1421-1430.

Kessler, R. C., Chiu, W. T., Jin, R., Ruscio, A. M., Shear, K., \& Walters, E. E. (2006). The epidemiology of panic attacks, panic disorder, and agoraphobia in the National Comorbidity Survey Replication. Archives of General Psychiatry, 63, 415-424.

Klein, D. F. (1993). False suffocation alarms, spontaneous panics, and related conditions. An integrative hypothesis. Archives of General Psychiatry, 50, 306-317.

Knuts, I. J., Cosci, F., Esquivel, G., Goossens, L., van Duinen, M., Bareman, M., et al. (2010). Cigarette smoking and 35\% CO(2) induced panic in panic disorder patients. Journal of Affective Disorders, 124, 215-218.

Kushner, M. G., Mackenzie, T. B., Fiszdon, J., Valentiner, D. P., Foa, E., Anderson, N., et al. (1996). The effects of alcohol consumption on laboratory-induced panic and state anxiety. Archives of General Psychiatry, 53, 264-270.

Lee, K., Noda, Y., Nakano, Y., Ogawa, S., Kinoshita, Y., Funayama, T., et al. (2006). Interoceptive hypersensitivity and interoceptive exposure in patients with panic disorder: Specificity and effectiveness. BMC Psychiatry, 6, 32.

Liotti, M., Brannan, S., Egan, G., Shade, R., Madden, L., Abplanalp, B., et al. (2001). Brain responses associated with consciousness of breathlessness (air hunger). Proceedings of the National Academy of Sciences of the United States of America, 98, 2035-2040.

Martinez, J. M., Coplan, J. D., Browne, S. T., Goetz, R., Welkowitz, L. A., Papp, L. A., et al. (1998). Hemodynamic response to respiratory challenges in panic disorder. Journal of Psychosomatic Research, 44, 153-161.

McLean, C. P., \& Anderson, E. R. (2009). Brave men and timid women? A review of the gender differences in fear and anxiety. Clinical Psychology Review, 29, 496-505.

Nardi, A. E., Valenca, A. M., Lopes, F. L., de-Melo-Neto, V. L., Freire, R. C., Veras, A. B. et al. (2007). Caffeine and 35\% carbon dioxide challenge tests in panic disorder. Human Psychopharmacology, 22, 231-240.

Nardi, A. E., Valenca, A. M., Lopes, F. L., Nascimento, I., Veras, A. B., Freire, R. C., et al. (2006). Psychopathological profile of $35 \% \mathrm{CO}_{2}$ challenge test-induced panic attacks: A comparison with spontaneous panic attacks. Comprehensive Psychiatry, 47, 209-214

Nillni, Y. I., Berenz, E. C., Rohan, K. J., \& Zvolensky, M. J. (2012). Sex differences in panic-relevant responding to a $10 \%$ carbon dioxide-enriched air biological challenge. Journal of Anxiety Disorders, 26, 165-172.

Olesen, J., Gustavsson, A., Svensson, M., Wittchen, H. U., \& Jonsson, B. (2012). The economic cost of brain disorders in Europe. European Journal of Neurology, 19, $155-162$.

Papadopoulos, A., Rich, A., Nutt, D. J., \& Bailey, J. E. (2010). The effects of single dose anxiolytic medication on the $\mathrm{CO}_{2}$ models of anxiety: Differentiation of subjective and objective measures. Journal of Psychopharmacology, 24, 649-656.

Pappens, M., De Peuter, S., Vansteenwegen, D., Van den Bergh, O., \& Van Diest, I. (2012). Psychophysiological responses to $\mathrm{CO}(2)$ inhalation. International Journal of Psychophysiology, 84, 45-50.

Perna, G., Brambilla, F., Arancio, C., \& Bellodi, L. (1995). Menstrual cycle-related sensitivity to $35 \% \mathrm{CO}_{2}$ in panic patients. Biological Psychiatry, 37, 528-532.
Perna, G., Caldirola, D., Namia, C., Cucchi, M., Vanni, G., \& Bellodi, L. (2004). Language of dyspnea in panic disorder. Depression and Anxiety, 20, 32-38.

Perna, G., di Bella, D., Favaron, E., Cucchi, M., Liperi, L., \& Bellodi, L. (2004). Lack of relationship between $\mathrm{CO}_{2}$ reactivity and serotonin transporter gene regulatory region polymorphism in panic disorder. American Journal of Medical Genetics Part B: Neuropsychiatric Genetics, 129B, 41-43.

Poma, S. Z., Milleri, S., Squassante, L., Nucci, G., Bani, M., Perini, G. I., et al. (2005). Characterization of a $7 \%$ carbon dioxide $\left(\mathrm{CO}_{2}\right)$ inhalation paradigm to evoke anxiety symptoms in healthy subjects. Journal of Psychopharmacology, 19, 494-503.

Poonai, N., Antony, M. M., Binkley, K. E., Stenn, P., Swinson, R. P., Corey, P., et al. (2000). Carbon dioxide inhalation challenges in idiopathic environmental intolerance. Journal of Allergy and Clinical Immunology, 105, 358-363.

Preter, M., \& Klein, D. F. (2008). Panic, suffocation false alarms, separation anxiety and endogenous opioids. Progress in Neuro-Psychopharmacology and Biological Psychiatry, 32, 603-612.

Richerson, G. B. (2004). Serotonergic neurons as carbon dioxide sensors that maintain pH homeostasis. Nature Reviews Neuroscience, 5, 449-461.

Richey, J. A., Schmidt, N. B., Hofmann, S. G., \& Timpano, K. R. (2010). Temporal and structural dynamics of anxiety sensitivity in predicting fearful responding to a $35 \% \mathrm{CO}_{2}$ challenge. Journal of Anxiety Disorders, 24, 423-432.

Sanchez-Meca, J., Rosa-Alcazar, A. I., Marin-Martinez, F., \& Gomez-Conesa, A. (2010). Psychological treatment of panic disorder with or without agoraphobia: A metaanalysis. Clinical Psychology Review, 30, 37-50.

Sasaki, I., Akiyoshi, J., Sakurai, R., Tsutsumi, T., Ono, H., Yamada, K., et al. (1996). Carbon dioxide induced panic attack in panic disorder in Japan. Progress in NeuroPsychopharmacology and Biological Psychiatry, 20, 1145-1157.

Schmidt, N. B., \& Zvolensky, M. J. (2007). Anxiety sensitivity and $\mathrm{CO}_{2}$ challenge reactivity as unique and interactive prospective predictors of anxiety pathology. Depression and Anxiety, 24, 527-536.

Schruers, K., Esquivel, G., van Duinen, M., Wichers, M., Kenis, G., Colasanti, A., et al. (2011). Genetic moderation of $\mathrm{CO}_{2}$-induced fear by 5-HTTLPR genotype. Journal of Psychopharmacology, 25, 37-42.

Schruers, K., van de Mortel, H., Overbeek, T., \& Griez, E. (2004). Symptom profiles of natural and laboratory panic attacks. Acta Neuropsychiatrica, 16, 101-106.

Senn, S. S. (2002). Cross-over trials in clinical research (2nd ed.). Chichester, England: John Wiley \& Sons Ltd.

Severson, C. A., Wang, W., Pieribone, V. A., Dohle, C. I., \& Richerson, G. B. (2003). Midbrain serotonergic neurons are central pH chemoreceptors. Nature Neuroscience, 6, 1139-1140.

Sheehan, D. V., Lecrubier, Y., Sheehan, K. H., Amorim, P., Janavs, J., \& Weiller, E. (1998). The Mini-International Neuropsychiatric Interview (M.I.N.I.): The development and validation of a structured diagnostic psychiatric interview for DSM-IV and ICD-10. Journal of Clinical Psychiatry, 59(Suppl. 20), 22-33.

Shufflebotham, J., Wetherell, M. A., Hince, D., Hood, S., Lightman, S., Nutt, D., et al. (2009). Women with diarrhoea-predominant irritable bowel syndrome show an increased pressure response to 35\% carbon dioxide stress challenge. Stress, 12, 30-36.

Smits, J. A., Meuret, A. E., Zvolensky, M. J., Rosenfield, D., \& Seidel, A. (2009). The effects of acute exercise on $\mathrm{CO}(2)$ challenge reactivity. Journal of Psychiatric Research, 43, 446-454.

Verburg, K., Griez, E., Meijer, J., \& Pols, H. (1995). Discrimination between panic disorder and generalized anxiety disorder by $35 \%$ carbon dioxide challenge. American Journal of Psychiatry, 152, 1081-1083.

Verburg, K., Perna, G., \& Griez, E. J. L. (2001). A case study of the $35 \% \mathrm{CO}_{2}$ challenge. In E. J. L. Griez, C. Faravelli, D. Nutt, \& J.Zohar(Eds.), Anxiety disorders. An introduction to clinical management and research (pp. 341-357). Chichester: Wiley.

Verburg, K., Pols, H., de Leeuw, M., \& Griez, E. (1998). Reliability of the $35 \%$ carbon dioxide panic provocation challenge. Psychiatry Research, 78, 207-214.

Verschoor, E., \& Markus, C. R. (2011). Physiological and affective reactivity to a 35\% $\mathrm{CO}(2)$ inhalation challenge in individuals differing in the 5-HTTLPR genotype and trait neuroticism. European Neuropsychopharmacology, 22, 546-554.

Vilarim, M. M., Rocha Araujo, D. M., \& Nardi, A. E. (2011). Caffeine challenge test and panic disorder: A systematic literature review. Expert Review of Neurotherapeutics, 11, 1185-1195.

Weissman, M. M., Bland, R. C., Canino, G. J., Faravelli, C., Greenwald, S., Hwu, H. G., et al. (1997). The cross-national epidemiology of panic disorder. Archives of General Psychiatry, 54, 305-309.

Wetherell, M. A., Crown, A. L., Lightman, S. L., Miles, J. N., Kaye, J., \& Vedhara, K. (2006). The four-dimensional stress test: Psychological, sympatheticadrenal-medullary, parasympathetic and hypothalamic-pituitary-adrenal responses following inhalation of $35 \% \mathrm{CO}_{2}$. Psychoneuroendocrinology, 31, 736-747.

Ziemann, A. E., Allen, J. E., Dahdaleh, N. S., Drebot, I. I., Coryell, M. W., Wunsch, A. M., et al. (2009). The amygdala is a chemosensor that detects carbon dioxide and acidosis to elicit fear behavior. Cell, 139, 1012-1021. 